EMBRYARIDDLE
Aeronautical University

SCHOLARLY COMMONS
International Journal of Aviation, Aeronautics, and Aerospace

\title{
Determination of rejected landing roll runway point-of-no-return and go-around in transport category airplanes
}

Nihad E. Daidzic, Ph.D., Sc.D.

AAR Aerospace Consulting, LLC, aaraerospace@cs.com

Follow this and additional works at: https://commons.erau.edu/ijaaa

Part of the Aerospace Engineering Commons, Applied Mechanics Commons, Aviation Commons, and the Engineering Physics Commons

\section{Scholarly Commons Citation}

Daidzic,, N. E. (2016). Determination of rejected landing roll runway point-of-no-return and go-around in transport category airplanes. International Journal of Aviation, Aeronautics, and Aerospace, 3(1). https://doi.org/10.15394/ijaaa.2016.1110

This Article is brought to you for free and open access by the Journals at Scholarly Commons. It has been accepted for inclusion in International Journal of Aviation, Aeronautics, and Aerospace by an authorized administrator of Scholarly Commons. For more information, please contact commons@erau.edu. 
The evidence shows and it has been recognized in aviation/airline industry, academia, and government regulatory and safety agencies that takeoffs and landings are singularly the most hazardous flight phases in commercial air transportation (FAA, 1994). More than $50 \%$ of all commercial aviation accidents occur during takeoffs and landings which combined represent no more than $5 \%$ of the average flight duration. While takeoffs are relatively well defined and the initial energy conditions are under full control, landings carry many uncertainties regarding the touchdown location and speed (kinetic energy content). Thus, landing operational regulations provide larger margins to allow for unavoidable variations in environmental, pilot, and aircraft conditions. Although it is desired that airplane touch down at a predetermined spot on the runway and at proper speeds, the operational experience has demonstrated wide margins in landing operations (FAA, 2007). Multiple reasons for that exist which will not be specifically discussed in this article.

One scenario rarely discussed and for which only few operators have even rudimentary standard operating procedures (SOP) is aborted landing roll and goaround after touchdown. While touch-and-go landings are quite common in light training airplanes (certified under FAR 23), transport category (T-category) airplanes (certified under FAR 25) normally never utilize such maneuvers. While fatal accidents have occurred after unsuccessful go-around following landing touchdown there is no known statistics, at least to this author, on how frequent such events are in commercial and business aviation industry.

Attempts of go-arounds after touchdown can be very hazardous and fatal. American Airlines Boeing 727-95 N1963 landed long at STT (St Thomas, US Virgin Islands) on April 17, 1976 (Job, 1994) which resulted in 37 fatalities out of 88 on board during unsuccessful landing-roll abort. After prolonged float in ground effect, the airplane touched down about 3,000 ft from the threshold of the very short 4,650-ft runway. Soon after touchdown and realizing it will not be able to stop on the remaining runway, the captain attempted to go around adding TOGA (Takeoff Go-Around) thrust. Then realizing that it would be impossible to lift off using what was left of the runway, the captain changed his mind again and tried to abort go-around and stop. As expected, the airplane exited the runway at high speed. Many fatalities occurred in the ensuing crash and fire.

On July 31, 2008, at about 09:45 AM central daylight time, a Hawker Beechcraft BAE 125-800A with registration N818MV was completely destroyed killing all 8 occupants when it impacted terrain at high speed during aborted landing roll and subsequent unsuccessful go-around from runway 30 at the Owatonna Degner Regional Airport (KOWA), Owatonna, Minnesota. The non- 
scheduled flight was operating under the provisions of Title 14 CFR Part 135. The instrument flight rules (IFR) flight plan had been filed and activated, but was cancelled before the landing. Visual meteorological conditions existed at the time of landing. However, severe thunderstorms passed through the area with heavy rain less than two hours before ill-fated Hawker crash.

Recent final National Transportation Safety Board (NTSB) ruling (ID: DCA08MA085) has confirmed that pilots of a Hawker Beechcraft 800A (BAe 125-800A) registration N818MV in Owatonna (KOWA in MN) on July 31, 2008 attempted unsuccessfully a go-around after long touchdown and poor braking efforts. NTSB final ruling says that pilots did not use brakes for 8 seconds after touchdown and simply did not attain the flying speed to escape the ground effect during attempted go-around, stalled, and crashed about $1,500 \mathrm{ft}$ beyond the runway threshold. A 1,000-ft long impact and crash deceleration distance existed beyond 1,500 ft touchdown in the corn field. Eyewitnesses said that the airplane tried to takeoff after it already touched down attempting to land. Additionally, severe thunderstorms passed through the area shortly before Hawker's attempted landing in KOWA. It was postulated by Daidzic (2008) that the absence of braking effort was most likely due to hydroplaning on a short 5,500 ft municipal airport runway. The NTSB reported not finding evidence of hydroplaning, but the question of why no braking effort was initiated for extended period remains unanswered.

Runway distances illustrated in Figure 1 are normally declared by respective airport authority following the applicable regulations and can be found in FAA's Airport/Facility (A/F) Directory. Takeoff Distance Available (TODA) includes Takeoff Run Available (TORA) plus clearway in which case clearway used in calculations cannot exceed 50\% of TORA (FAA, 2013, 2014a; Jeppesen, 2007; Padilla, 1995; Swatton, 2008). Accelerate-Go Distance Available (ASDA) includes TORA and stopway while Landing Distance Available (LDA) may or may not be equal to TORA (FAA, 2014a). That will depend on the availability of displaced threshold and if the stopway is included in LDA. Sometimes Engineered Materials Arresting Systems (EMAS) are placed at the far end of the runway to slow down and/or stop overrunning airplanes (Daidzic and Shrestha, 2008; FAA, 2012). EMAS, of course, cannot be a part of stopway or LDA (FAA, 2012). DeLoach et al. (2009) performed analysis of landing overrun with uncertainty analysis for the evaluation of a passive runway arresting system.

Gross or un-factored (ASD, TOR, TOD) and net or factored (ASDR, TORR, TODR) takeoff distances are illustrated in Figure 2. Airplane weight must be adjusted for existing environmental and atmospheric conditions so that 
required distances do not exceed available distances. Runways are often unbalanced (Balanced Filed Length or BFL) and ASDA is not equal to TODA if stopways and clearways of various lengths exist (Swatton, 2008). Factored AllEngines Operating (AEO) and unfactored One-Engine Inoperative (OEI) takeoffs are compared for both dry and wet runways (FAA, 2013; Jeppesen, 2007; Swatton, 2008). If no clearway exists TODA restricts accelerate-go takeoff, while with significant clearway length, TORA may be more restrictive than TODA.

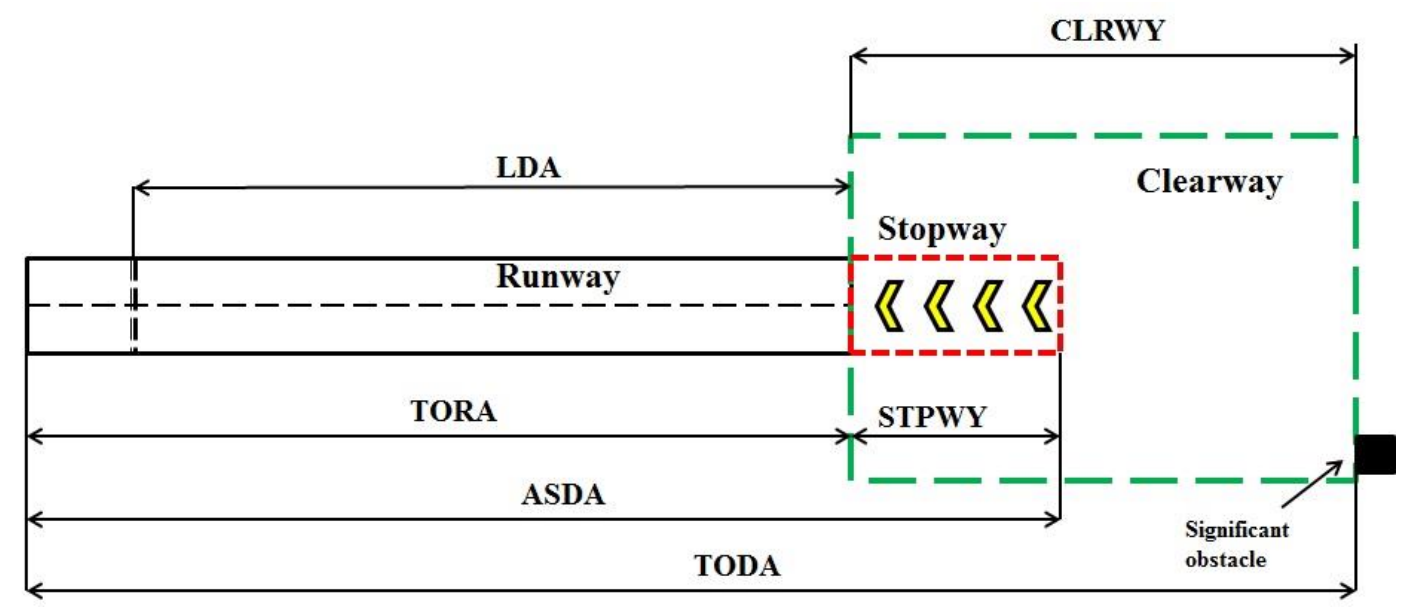

Figure 1. Generic layout of airport declared distances. Can vary significantly in real life based on airport architecture. Not to scale.

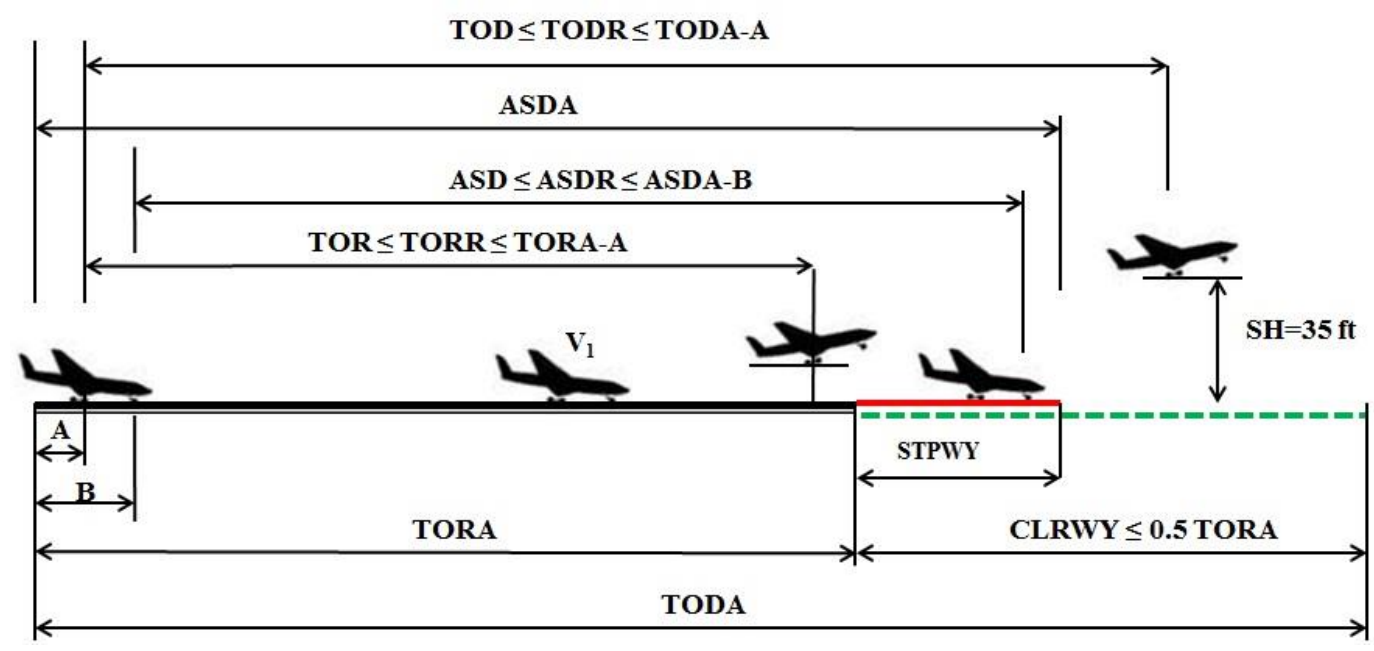

Figure 2. Regulatory takeoff distances defined. Not to scale. 
Landing runway requirements for commercial public air transportation are spelled out in operational regulations (e.g., 121, 135, etc.). Transport-category airworthiness certification rules such as Title 14 CFR 25.125 (FAA 2013) only specify gross performance and conditions under which gross landing performance was obtained. DLD is gross (un-factored), sometimes also called demonstrated, landing distance on dry runway which was derived from the measured certification flight tests and averaged for the fleet of particular airplane make and models. DLDR is factored or net dry landing distance required accounting for operational performance cushions (Daidzic, 2009c; FAA, 2014b). WLDR is the required net landing distance for generic wet runways and does not implicitly or explicitly include contaminated runways. Damp runways are often treated as wet runways, but they may become very slippery under specific conditions. Required distances can never exceed available distance. Landing requirements are illustrated in Figure 3 (FAA, 2014b).

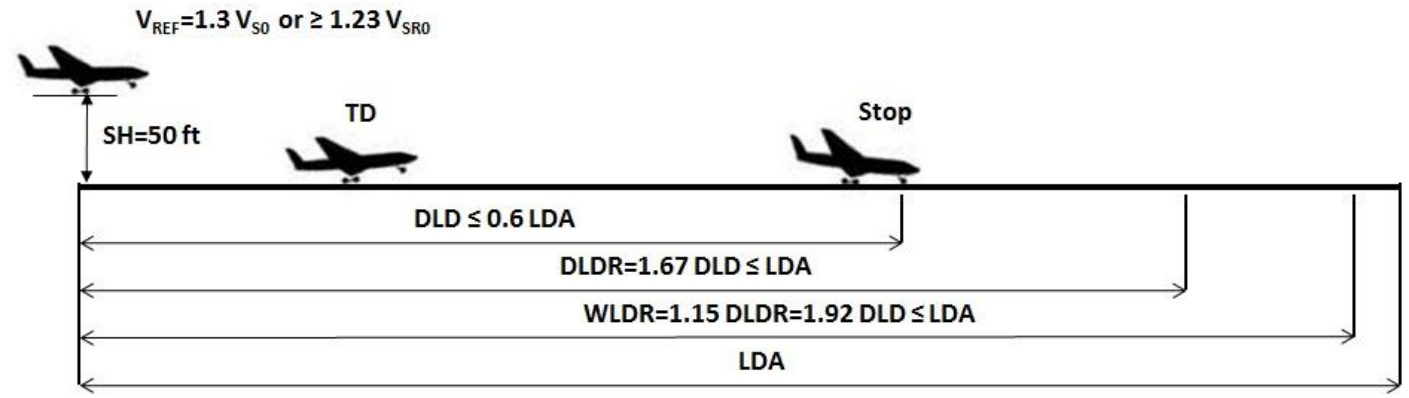

Figure 3. Regulatory landing distances defined. Not to scale.

A schematic of the landing decelerate-accelerate-takeoff maneuver with the dynamic PNR location is illustrated in Figure 4. Unlike Rejected Takeoffs (RTO) and $\mathrm{V}_{1}$ (decision/action) speeds there is no assurance that the landing airplane will indeed stop by the end of LDA. Thus a concept of rejected landing ground roll is introduced (RLR) with the PNR-speed taking the primary role in decision making process. The rejected-landings (decelerate-accelerate) are fundamentally different from, and inverse of, the RTO's (accelerate-decelerate). While takeoff maneuver, if done properly, will guarantee that the airplane will or fly when OEI or stop by the end of ASDA, no such guarantee exists for the landing PNR maneuver and the airplane can get in the situation where it cannot go-around nor can it stop on the remaining runway.

The main idea behind runway landing PNR-concept is thus to define a speed from which it is still possible, after initial deceleration, to continue OEI goaround takeoff. Operational regulations may require reaching certain minimum 
screen height (SH) at departure end of the runway (DER). However, it is almost impossible to schedule or plan PNR speeds in line operations as the landing maneuver is very dynamic with many variables and uncertainties affecting the exact location of touchdown and kinetic energy carried by the aircraft.

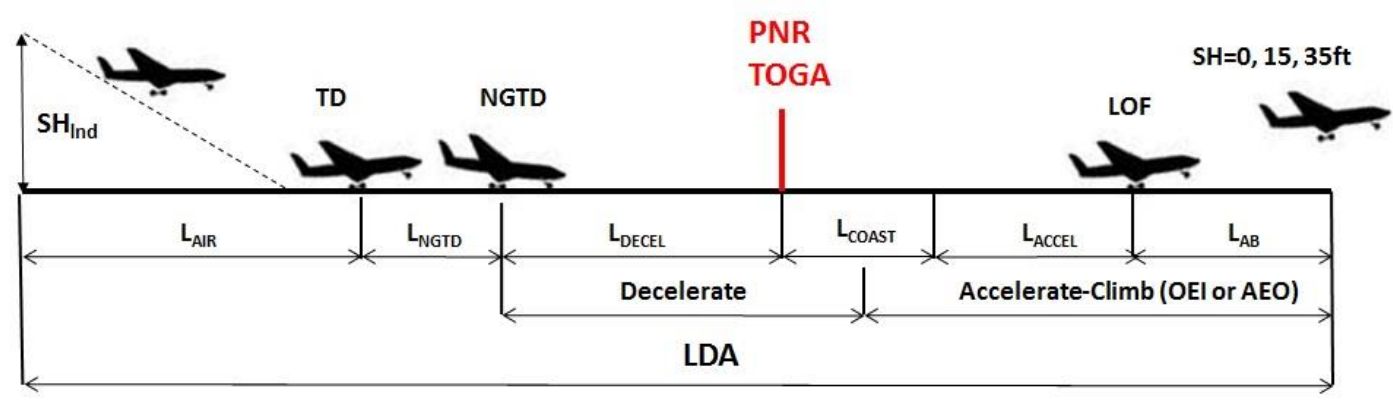

Figure 4. Landing decelerate-accelerate landing-roll go-around maneuver with PNR. Nose-gear touchdown (NGTD) typically occurs 3 seconds after main-gear touchdown (TD). Not so scale.

The NTSB used designation commit-to-land point for the landing PNR we use here. However, PNR can be seen more as a last-chance commit-to-go-around point. Not changing anything and just continuing deceleration efforts and disregarding runway PNR is a default solution albeit one that does not ensure full stop on the runway. It takes a dynamic effort to change both, the human and the airplane inertia, and switch from stop-stop to go-go mental attitude (Daidzic, 2008, 2009a). As it happened in the unfortunate case with B727 in 1976 it is a very difficult decision to make and pilots are normally not trained for this scenario. There is absolutely no space for confusion or indecision in the cockpit when aborted (rejected) landing decelerate-accelerate-takeoff decision must be made.

The main purpose of this research article is to provide deeper physical insights and deliver a comprehensive novel theory based on the aircraft's total energy. This approach would still result in a reasonably accurate models for rejected landing PNR determination as a function of many aforementioned variables and parameters.

\section{Literature Review}

While touch-and-go landing practice is quite frequent in flight training, little was found on equivalent maneuver in commercial air transportation. It seems that few operators even consider such an option exists and no SOPs or training is 
available to guide pilots. No statistical data was found on frequency of landing go-arounds. Only those unfortunate and unsuccessful few are well known.

Takeoff dynamics of rigid airplanes is described in various levels of detail in several standard and classical aerospace/aeronautics engineering references (Anderson, 1999; Asselin, 1997; Davies, 2003; Eshelby, 2000; Filippone, 2006; Hale, 1984; Mair and Birdsall, 1992; McCormick, 1995; Padilla, 1996; Roskam and Lan, 1997; Saarlas, 2007; Shevell, 1989; Torenbeek and Wittenberg, 2009; Vinh, 1993). Blake and Elliot (1991) discuss the final few minutes during airplane approach and landing. Authors reported one landing overrun per 3.6 million flights. In 1990, that would have been one landing overrun every 3 months in USA. However, today, 60 to 80 overruns occur in commercial air transportation worldwide utilizing T-category airplanes every year (Daidzic, 2009a). Progress achieved in improving approach-and landing safety was discussed by McKinney (1999). The author highlighted some recommendations for the reduction and elimination of approach-and-landing accidents. But despite all the efforts to reduce accidents during landing phase, the same operational errors and difficulties stubbornly persist. van Es et al. (2001) discuss the safety aspects of aircraft performance on wet and contaminated runways by studying sample of 91 overruns and veer-offs. Based on a sample of European airports there appeared to be four-fold increase in accident risk for aircraft operating on wet and contaminated runways. The authors suggest that go-arounds should be considered whenever fast and long landings on wet and contaminated runways are expected. van Es (2005) performed analysis of landing overrun accidents over the period of 35 years.

In-depth development of landing dynamics models and computational simulations incorporating differing pilot techniques and variable runway and environmental conditions was conducted by Daidzic and Shrestha (2008). Programs developed from that research can be used for accident investigations and solution of inverse problems. Daidzic (2009a, 2009c) provides further analysis of braking action on contaminated surfaces accounting for many physical factors including anti-skid operation and physics of tire-surface friction forces. The calculations of veer-offs on contaminated/slippery runways in the presence of crosswind were presented in Daidzic (2009b). van Es (2010) performed a study of runway excursions from a European perspective. Both, takeoff and landing overruns and veer-offs were analyzed for the runway excursions occurring in the period of 1980-2008. The author also discusses some technical solutions by Airbus, Boeing, and Honeywell to reduce landing overruns. Daidzic (2011a, 2011b) further discusses contaminated runways and operations. 
Takeoff problems on contaminated runways in the presence of crosswind that may result in veer-offs and the role of thrust-reversers in such situations were discussed by Daidzic (2013a). Takeoff considerations and certification of Tcategory airplanes was discussed in Daidzic (2013b). Special takeoff techniques such as overspeed takeoffs were considered in Daidzic (2014).

Over the last 60 years many attempts were made to assist pilots with takeoff performance monitors (TOPM). Takeoffs are critical for flight safety and the airplane is heaviest with smallest performance margins (FAA 1994). All the performance measures are based on speeds without actually measuring distances. This can only work if the scheduled accelerations (AEO or OEI) are actually met in practice. Monitoring acceleration, speed, and distance during takeoffs and then predicting future performance is very important, but that has defied engineers and designers so far. More details on takeoff performance monitors can be found in Wagenmakers (1991). Zammit-Mangion and Eshelby (2005) discussed design and integration of a take-off monitor display in cockpit environment. Recently, Zammit-Mangion and Eshelby (2006) have studied flight tests of large T-category jet and twin turboprop airplanes. Predictive algorithms were developed which according to authors were well within the SAE's aerospace standard AS-8044 thus warranting adoption in TOPM.

While rejected landing and go-around has been mentioned cursory in some older materials, no scientific consideration and discussion was ever conducted. To the best of our knowledge the first analytical consideration and computation of the PNR speeds, distances and time was given by Daidzic (2008). That analysis specifically focused on the Hawker 800A unsuccessful go-around and crash in Owatonna, MN in 2008. More in-depth discussion on landing PNR was then treated in Daidzic (2009a) and Daidzic (2011b). Most recent contribution toward this topic was given by Daidzic (2016) in which also the need for SOPs and design of runway energy monitoring and management systems was emphasized. Essentially, in all previous analytical studies simpler algebraic rejected-landing PNR models were presented with computational methods on how to determine landing PNR speed and time for given touchdown conditions.

\section{Mathematical Models and Methodology}

The entire dynamics of landing go-around PNR could be simulated with differential equations of motion in an appropriate reference systems. Many additional algebraic relationships would be required to describe constitutive and other relationships. Such large system of strongly nonlinear ODE (Ordinary Differential Equations) could be numerically integrated in time to provide the 
entire history of motion. The model could be made as complicated as one desires with probably in excess of 50 simultaneous differential and algebraic equations. Due to excessive complexity, we chose to present simpler model based on the total energy conservation principle, while taking into account average forces and accelerations over finite time intervals. Such exercise will facilitate better understanding of the critical influences with still reasonably accurate model.

\section{Landing dynamics}

Ideally, transport category airplane crosses runway threshold at a given landing screen height (regulatory for certification is $50 \mathrm{ft}$ ) and given reference airspeed $\mathrm{V}_{\mathrm{REF}}$, initiates short flare (roundout) maneuver at appropriate height (typically 10-30 ft), touches down and promptly lowers the nose gear (recommended within 3 seconds), and initiates deceleration ground roll utilizing friction braking and thrust reversers. For all practical purposes aerodynamic drag during landing roll can be neglected other than for extremely slippery contaminated runways where deceleration levels are so low that even aerodynamic drag plays relatively important role (Daidzic and Shrestha, 2008). The landing dynamic equations are set in a non-orbiting flat-Earth, approximately inertial, frame of reference as the distances are short and non-inertial effects negligible (Daidzic and Shrestha, 2008). The fundamental equations of motion in horizontal and vertical planes which describe decelerating ground roll at constant airplane mass and arbitrary wind, yield:

$$
\begin{aligned}
& \frac{d v}{d t}=g \cdot\left[\left(\frac{T}{W}\right)_{r}-\left(\frac{D}{W}\right)_{\text {aero }}-\mu_{B}(s)\left(\frac{N}{W}\right) \pm \sin \phi_{R W Y}\right]<0 \\
& \frac{d s}{d t}=v_{G S}=v \pm v_{w} \\
& \frac{d w}{d t}=g \cdot\left\{\frac{L(\sigma, v)}{W}-\cos \phi_{R W Y}+\frac{N}{W}\right\}=0 \\
& \frac{d h}{d t}=w=0 \quad s=s_{T D} \quad v=v_{T D} \quad h=h_{0}=0 \quad w=w_{0}=0 \quad W=W_{0}=L W=\text { const. }
\end{aligned}
$$

The airborne part (descent-decelerate), flare, main-gear and nose-gear touchdown dynamics is not included in above differential model. Almost all the terms on the RHS of the horizontal dynamics in Equation (1) are functions of the true and ground speed, air density, airplane's geometry, and aerodynamic characteristics. The first term or the (T/W)-ratio can be or slightly positive 
(residual thrust and no thrust reversers) or significantly negative by using thrust reversers and contributing to deceleration. The second term is the aerodynamic drag which often is very small compared to other contributions and when then really only at higher speeds. The third term is the generally spatially-dependent friction braking term and overwhelmingly the most important decelerating force on dry runway. Only when the runways are contaminated and significantly slippery does this term become small. This coefficient could also take into full consideration pilot's braking efforts and the anti-skid system braking efficiency (Daidzic, 2009a, 2011a, 2011b, 2013a). The last term can be both negative and positive along the runway designating local runway slope, which for most commercial airports/runways can be neglected (less than $2 \%$ ). Additionally, for most nearly-level runways, we can reasonably substitute $\sin \phi_{R W Y} \approx \phi_{R W Y}$ and $\cos \phi_{R W Y} \approx 1$, with angles expressed in radians.

The air distance covered in flare for which descent angle is assumed positive (although it is negative as negative net thrust exists) can be approximated by:

$$
L_{A I R}=\frac{S H_{L N D}}{\left(\frac{1}{E}\right)_{L N D}-\left(\frac{T}{W}\right)_{L N D}}+\frac{v_{S H}^{2}-v_{T D}^{2}}{2 \cdot \bar{a}_{L N D}}=\frac{S H_{L N D}}{E_{e f f, L N D}}+\frac{E_{e f f, F L R}}{2 \cdot g}\left(v_{S H}^{2}-v_{T D}^{2}\right)
$$

where:

$$
E_{e f f, L N D}=\left[\left(\frac{1}{E}\right)_{L N D}-\left(\frac{T}{W}\right)_{L N D}\right]^{-1} \quad E_{e f f, F L R}=\left[\left(\frac{1}{E}\right)_{L N D}-\left(\frac{T}{W}\right)_{F L R}\right]^{-1}
$$

The aerodynamic efficiency is defined as $E=L / D$. During flare, the throttles are typically pulled back to flight idle which in most modern turbofans is about $7-10 \%$ of the maximum thrust for given air pressure and temperature. Landing flare is accelerated maneuver (Daidzic and Shrestha, 2008) during which kinetic energy is dispensed to slow down potential energy (height) loss. To simplify the problem, in the future landing considerations the landing air distance will be a simple input together with the touchdown speed. Details of flare dynamics and speed decrement during flare (from threshold crossing to touchdown), which often is small unless prolonged floating in ground effect occurs, thus need not be considered at all. For details on this see Daidzic and Shrestha (2008) and Daidzic (2009a, 2009c). 


\section{Takeoff dynamics}

Expanded basic differential equations of motion of rolling rigid aircraft of variable mass on a perfectly rigid surface are (Daidzic, 2014):

$$
\begin{aligned}
& \frac{d W}{d t}=-T(\sigma, v) \cdot g \cdot \operatorname{SFC}(\theta, v)<0 \\
& \frac{d v}{d t}=g \cdot\left\{\frac{T(\sigma, v)-D(\sigma, v)}{W}-\mu_{r}(s)\left(\frac{N}{W}\right) \pm \sin \phi_{R W Y}-\frac{v}{W g} \frac{d W}{d t}\right\}>0 \\
& \frac{d s}{d t}=v_{G S}=v \pm v_{w} \\
& \frac{d w}{d t}=g \cdot\left\{\frac{L(\sigma, v)}{W}-\cos \phi_{R W Y}+\frac{N}{W}\right\}=0 \\
& \frac{d h}{d t}=w=0 \\
& I C s: \quad s=s_{0} \quad v=v_{0} \quad h=h_{0}=0 \quad w=w_{0}=0 \quad W=W_{0}=T O W
\end{aligned}
$$

However, other phases of takeoff must be accounted for as well, which includes rotation, lift-off and initial climb to $\mathrm{SH}$ all of which tremendously complicates model analysis. The coupled system of nonlinear ODE presented with Equation (3) is valid up to the point of rotation. The reactive thrust component (rocket-thrust) is negligible for conventional jet-engine airplanes. The complexity of the system which describes sufficiently-well the takeoff ground run of rigid airplanes is obvious. Dynamics of many subsystems, such as, shock absorbers is not included. The rolling friction coefficient for airplane tires on dry concrete or asphalt runways is typically between 0.02 and 0.05 (Asselin, 1997; Saarlas, 2007). This rolling friction coefficient is also a function of groundspeed. Runway slope changes continuously along runway, but for most applications this term is small. Instead of using differential models, such as those presented by Equations (1) and (3), we will be using integral algebraic models based on the energy conservation principles which tremendously simplifies the analysis.

The crucial difference between takeoffs, which are well defined, and landings, which are not so well defined in terms of actual location and energy state, exists. Normal takeoff starts from the runway start (Brake Release Point or BRP of TORA) and is reduced by mandatory runway alignment corrections and/or running-takeoff correction (Swatton, 2008). On the other side, the location of aircraft during landing is variable with standard deviations exceeding $500 \mathrm{ft}$. Many studies have shown significant variations in airplane touchdown points 
during line operations (FAA, 2007; Mair and Birdsall, 1992). It is not uncommon for a wide-body jet to touch down past the 3,000-ft runway marker followed by frantic braking efforts attempting to rapidly dissipate airplane's kinetic energy. However, as airplane already carries some kinetic energy that may be beneficial if subsequent takeoff/go-around after touchdown is attempted.

Using the energy and power conservation law in integral form (Anderson, 1999; Asselin, 1997; Eshelby, 2000; Hale, 1984; Mair and Birdsall, 1992; McCormick, 1995; Saarlas, 2007; Vinh, 1993), yields:

$$
\underbrace{\frac{T \cdot v}{W}}_{\substack{\text { Energy } \\
\text { generation }}}-\underbrace{\frac{D \cdot v}{W}}_{\substack{\text { Energy } \\
\text { dissipation }}}=\underbrace{\frac{d h}{d t}}_{\begin{array}{c}
\text { Potential } \\
\text { Energy }
\end{array}}+\underbrace{\frac{v}{g} \frac{d v}{d t}}_{\begin{array}{c}
\text { Kinetic } \\
\text { Energy }
\end{array}}
$$

This equation can be rearranged to yield:

$$
d x=\frac{W}{[T(v)-D(v)]} \cdot\left(d h+\frac{1}{g} v d v\right)
$$

This is particularly useful expression when considering horizontal distance covered during airborne (climb-acceleration) part of takeoff (similar to landing air run) for which integral results in:

$$
L_{A B}=\int_{L O F}^{S H} d x=\left[\frac{W}{(T-D)}\right]_{a v}\left(\int_{0}^{S H} d h+\int_{L O F}^{S H} \frac{1}{g} v d v\right)=\left[\frac{W}{(T-D)}\right]_{a v}\left(\frac{v_{S H}^{2}-v_{L O F}^{2}}{2 \cdot g}+S H\right)
$$

The average net thrust-to-weight ratio is essentially an inverse of the average angle of climb since we know that approximately (Anderson, 1999; Asselin, 1997; Eshelby, 2000; Hale, 1984; Padillla, 1996; McCormick, 1995; Saarlas, 2007):

$$
\sin \gamma \approx \gamma=\frac{T-D}{W} \approx\left(\frac{T}{W}\right)-\frac{1}{E} \quad E=\frac{L}{D} \quad L \approx W
$$

The SH at DER can be set to an arbitrary value (typically between 0 and $35 \mathrm{ft}$ ) as dictated by operational regulations and safety standards. The SH-speed is typically taken to be $V_{2}$ (takeoff decision speed) and we could use the same reasoning by setting $\mathrm{V}_{\mathrm{SH}}=\mathrm{V}_{2}$ for given weight. Interestingly, for many T-category 


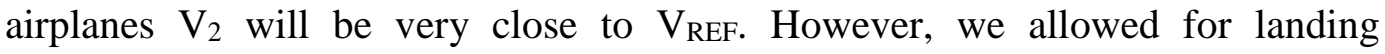
threshold speeds to be in excess of desired reference speed to account for operational problems.

\section{Determination of PNR}

Using graphic illustration in Figure 4, the entire landing go-around PNR dynamics can be now formulated with a simple algebraic inequality:

$$
L_{A I R}+L_{N G T D}+L_{D E C E L}+L_{C O A S T}+L_{A C E L}+L_{A B} \leq L D A
$$

The extremal condition is achieved when the inequality is substituted with the equality maximally utilizing LDA. Two main assumptions are made here. First, the speed loss in flare is neglected. This is reasonable approximation and practice shows that on-average airplanes lose about 3-5 knots in flare other than in case of long and extended float (FAA, 2007). Second, the airplane does not lose any speed during nose-gear de-rotation which is reasonably decent first approximation resulting in $\mathrm{V}_{\mathrm{TD}}=\mathrm{V}_{\mathrm{NGTD}}$. $\mathrm{A}$ conventional transport category airplane for which aerodynamic braking at high-AOA is negligible touching down at about 130 knots may only lose 2-3 knots during de-rotation mostly due to rolling friction and aerodynamic drag at high AOA.

Once throttles are applied for go-around, deceleration level will start decreasing, but deceleration cannot instantly mutate into acceleration as that would require forces of infinite magnitude. This "coasting" phase depends on many factors, including, engine acceleration characteristics (Daidzic, 2012a), the position and use of thrust-reversers, pilot reaction time, changing airplane drag and high-lift configuration, etc.

The entire rejected-landing PNR event can be seen in terms of the total energy state as illustrated in Figure 5. Landing aircraft has both potential and kinetic energy and must regain both for safe takeoff. The potential energy is dissipated upon touchdown and the remaining kinetic energy is supposed to be fully dissipated before the end of the LDA. If the kinetic energy cannot be dissipated by the end of LDA, an option may exist for which the airplane may use remaining runway to gain enough kinetic and potential energy and execute safe go-around. Various average acceleration and deceleration levels are shown in Figure 5. In the case of deceleration, two extremes exists - dry and contaminated (slippery) runways. In the case of acceleration, two extreme acceleration levels exist - AEO and OEI. Twin-jets are especially vulnerable to a loss of thrust on one engine. That is why their engines are disproportionally larger than in tri-jets 
or four-jet airplanes as field requirements must be met under reasonable conditions when OEI. If the aircraft touched down long and/or fast that will shift all deceleration lines to the right leaving less space for rejected landing. For a successful go-around, an airline simply must achieve total energy level by the end of LDA. Under the assumption that there is no significant speed-loss during nosegear de-rotation, we may write conservatively:

$L_{N G T D}=v_{T D} \cdot \Delta t_{N G T D}$

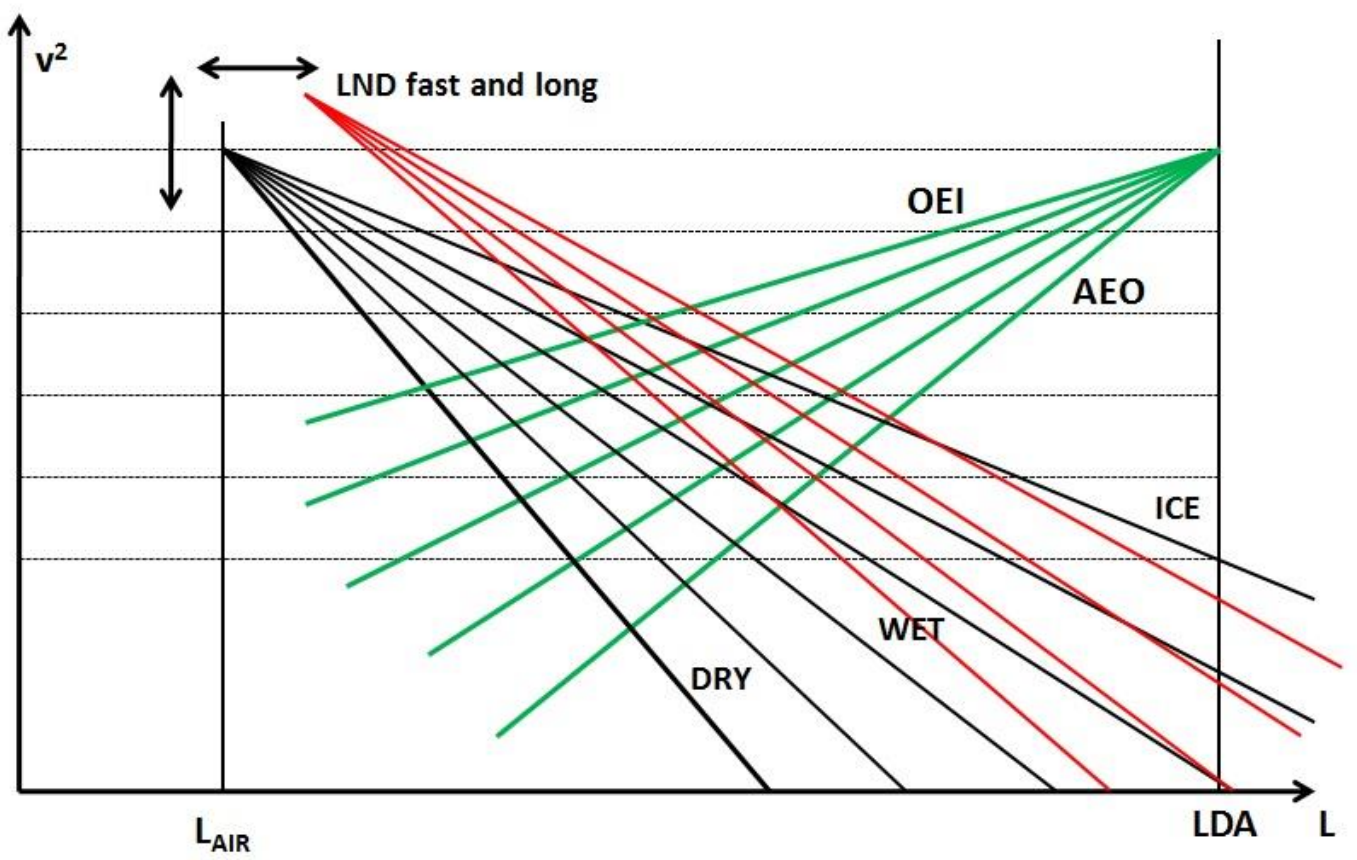

Figure 5. Average acceleration (AEO and OEI) and deceleration (dry, wet, contaminated) levels. Deviations in touchdown location and speed are illustrated as well. Not so scale.

Slowing down in landing roll can be described using average deceleration values from $\mathrm{V}_{\mathrm{TD}}$ to $\mathrm{V}_{\mathrm{PNR}}$, after which the decision is made to go-around and TOGA thrust/power is applied. In order to avoid using negative signs which only causes confusion, we just use absolute value of deceleration magnitude:

$L_{D E C E L}=\int_{T D}^{P N R} \frac{v d v}{-\left|\bar{a}_{D E C}\right|}=\frac{v_{T D}^{2}-v_{P N R}^{2}}{2 \bar{a}_{D E C}}>0 \quad \bar{a}_{D E C}>0 \quad v_{T D} \geq v_{P N R}$ 
T-category jets typically decelerate at a rate of 1 to $8 \mathrm{knot} / \mathrm{s}$, depending on the runway condition and combined braking effort. Similarly to FAR 25.109 (FAA, 2013) for the determination of ASDR, coasting at $V_{P N R}$ for a given time interval (2-4 seconds), during which deceleration changes into acceleration (inertia configuration change) is calculated from:

$L_{C O A S T}=v_{P N R} \cdot \Delta t_{C O A S T}>0$

The acceleration phase which will be assumed OEI only (decision to go coincides with engine failure and OEI continuing takeoff condition):

$$
L_{A C E L}=\frac{v_{L O F}^{2}-v_{P N R}^{2}}{2 \bar{a}_{A C C}}>0 \quad \bar{a}_{A C C}>0 \quad v_{L O F} \geq v_{P N R}
$$

The acceleration will depend if AEO or OEI and atmospheric conditions. Typically, average AEO acceleration is 5-6 knot/s while average OEI acceleration is 2-3 knot/s. The last remaining part is the airborne (AB) takeoff phase extending from LOF to SH condition. Various takeoff regulations (FAR 25.105 to 25.113) for dry and wet runways can be extended to require particular $\mathrm{SH}$ at the end of LDA (FAA, 2013). Thus we can write using Equation (6):

$$
L_{A B}=\frac{1}{\gamma_{T O}} \cdot\left(\frac{v_{S H}^{2}-v_{L O F}^{2}}{2 \cdot g}+S H\right) \quad \gamma_{T O}=\left(\frac{T}{W}\right)_{T O}-\left(\frac{1}{E}\right)_{T O}
$$

Substituting Equations (9-13) into Equation (8) for an identity extremal solution and performing required reductions, we arrive at a simple quadratic equation for estimation of unknown $\mathrm{V}_{\text {PNR }}$ speeds:

$$
A \cdot v_{P N R}^{2}+B \cdot v_{P N R}+C=0
$$

Where:

$$
\begin{aligned}
& A=\left(\frac{\bar{a}_{D E C}+\bar{a}_{A C C}}{2 \bar{a}_{D E C} \bar{a}_{A C C}}\right)>0 \quad B=-\Delta t_{C O A S T} \leq 0 \\
& C=L D A-\left[L_{A I R}+v_{T D} \Delta t_{N G T D}+\frac{v_{T D}^{2}}{2 \bar{a}_{D E C}}+\frac{v_{L O F}^{2}}{2 \bar{a}_{A C C}}+\frac{1}{\gamma_{T O}}\left(\frac{v_{S H}^{2}-v_{L O F}^{2}}{2 \cdot g}+S H\right)\right]
\end{aligned}
$$


where:

$$
\gamma_{T O}=\left(\frac{T}{W}\right)_{T O}-\left(\frac{1}{E}\right)_{T O}=\left(\frac{T}{W}\right)_{e f f} \quad \Delta t_{C O A S T}=2 \mathrm{sec} \quad \Delta t_{N G T D}=3 \mathrm{sec}
$$

The aerodynamic efficiency for T-category airplanes in takeoff configuration is typically between 10 and 12 . We assumed the value of 10 . In the landing configuration the aerodynamic efficiency is closer to 6 (six) for modern jetliners with high-lift devices fully deployed. Thrust-to-Weight $(T / W)$ ratio will depend on AEO or OEI condition. Thrust of modern turbofans is a function of TAS and density ratio Daidzic (2012a, 2012b).

The coefficient $\mathrm{C}$ is critically important in that it defines the specific total energy extracted from the available runway for deceleration-acceleration-takeoff maneuver. If $\mathrm{C}<0$, a solution is real and $\mathrm{V}_{\mathrm{PNR}}$ exists. However, if $\mathrm{C}$ is sufficiently large negative real number than $\mathrm{V}_{\mathrm{PNR}}>\mathrm{V}_{\mathrm{TD}}$, which means the solution is not feasible. If $\mathrm{C}=0$, one $\mathrm{V}_{\mathrm{PNR}}$ solution is zero. For all other cases $\mathrm{C}>$ 0 , the solution does not exist (complex solutions) and $\mathrm{V}_{\mathrm{PNR}}$ would be effectively less than zero meaning that we can operationally set it to zero. Such is a scenario commonly used by light-planes safely conducting touch-and-go landing practice on very long runways. Excess of runway implies also that an overspeed takeoff for better climb performance could be implemented (Daidzic, 2014).

Regular $V_{\text {PNR }}$ could vary between zero and $V_{T D}$ speed. If the runway is excessively long it is easy to imagine that an airplane could slow down to a full stop and then start from standstill. Such solution is often irrelevant as that would imply that the airplane can indeed stop on the runway. A possible utilization of such a solution would be if go-around is accomplished for other reasons other than weak braking deceleration. An example could be the inability to comply with LAHSO instructions after touchdown. The other extreme implies short runway for which the airplane must execute go-around instantly after touchdown. If the remaining runway is shorter than this condition, the airplane in landing roll cannot stop or go on the remaining runway - a very precarious situation. Such situation could also arise from a long and/or fast landing even on dry runways.

The airplane carries kinetic energy upon touchdown, which can be used toward supplementing total energy required for a safe go-around. Further, we assumed for this simple energy-conservation model that:

$$
v_{T D}=v_{N G T D} \quad v_{S H}=v_{2}(W) \quad v_{L O F}=1.15 \cdot v_{S 1} \quad v_{S H}=1.20 \cdot v_{S 1}
$$


The two possible real solutions of Equation (14) may be or double (identical) real root or two different real roots. Calculating the coefficient $\mathrm{C}$ represents the most daunting part in solving this nonlinear algebraic equation, for which the solution may be written (Spiegel and Liu, 1999):

$v_{P N R}^{I / I I}=\frac{-B \pm \sqrt{D}}{2 \cdot A} \quad D=B^{2}-4 \cdot A \cdot C \geq 0 \quad$ (Real roots)

Only larger positive real solution for the $V_{\text {PNR }}$ could be accepted for operational use unless other conditions allow for both real positive solutions. If one neglects the nose-gear touchdown delay and dynamics, then $\mathrm{B}=0$ and only one real (positive) solution exists:

$v_{P N R}=+\sqrt{\frac{-C}{A}}$

In another special case for which $\mathrm{C}=0$, two real solutions exist:

$v_{P N R}^{I}=0 \quad$ and $\quad v_{P N R}^{I I}=-\frac{B}{A}$

A kinetic energy versus runway length for a generic T-category airplane executing go-around after touchdown and initial acceleration is shown in Figure 6. After nose-gear touchdown an airplane has certain kinetic energy which may or may not be dissipated by the end of a runway. Energy dissipation will depend on the deceleration rates (deceleration forces and landing mass). If go-around is necessary then airplane must gain safe total energy level (kinetic and potential) by the end of the runway. The kinetic energy requirements are typically an order-ofmagnitude (or more) larger than potential energy amounts during takeoffs and landings.

It follows from Figure 6 that if the initial deceleration is high, an airplane can slow down to lower PNR speeds while using less runway before initiating goaround maneuver. If the deceleration is weak, the PNR speed is higher and more runway is used to slow down to it. Clearly as less runway is available to reach safe total energy requirements, the airplane must acquire more kinetic energy at the moment it rejects landing roll and executes go-around. This implies that: $v_{P N R}($ slow deceleration $)>v_{P N R}($ fast deceleration $)$. 


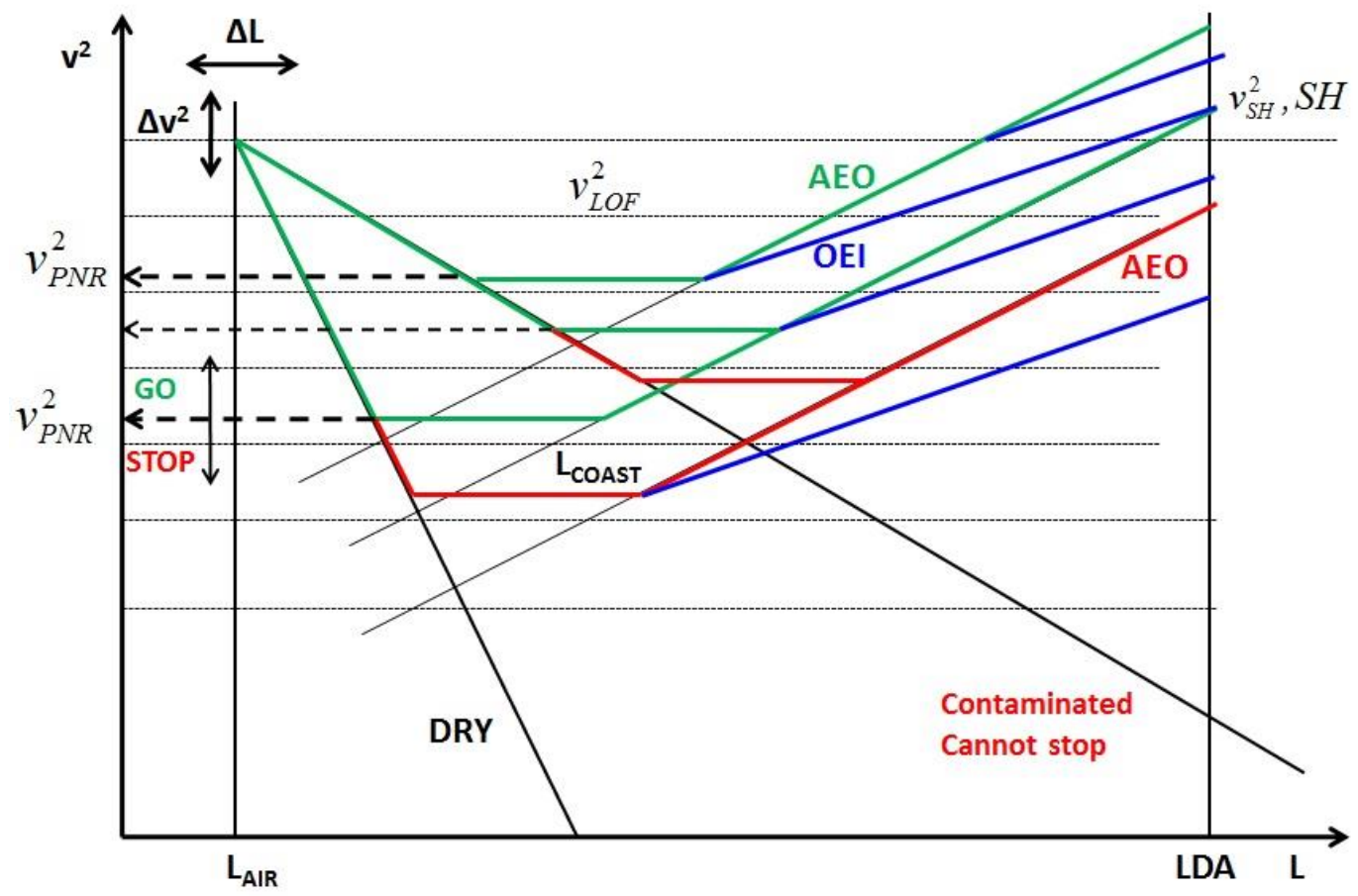

Figure 6. Average landing PNR acceleration and deceleration levels. It is inverse of the takeoff phase, i.e., it is decelerate-go maneuver. Not so scale.

In order to demonstrate the fundamental difference between the rejected landing roll go-around and regular takeoffs, an illustration of takeoff-energy versus distance is shown in Figure 7. The specific kinetic energy (per mass) was used on the vertical axis. Again, the average acceleration magnitudes are utilized, whereas instant accelerations constantly change (jerk or surge). Takeoff is well defined maneuver where the aircraft is always assured of continuing takeoff when OEI or stopping by the end of ASDA.

The average acceleration or deceleration, which by definition is constant, can be used to estimate acceleration distances, according to a simple kinematic expression:

$$
L=\frac{v^{2}}{2 \bar{a}_{A C C}}>0 \quad \bar{a}>0
$$

Results of computations that include typical accelerations and decelerations for takeoffs and landings are shown in Figure 8. For average acceleration factor of 
$0.05 \mathrm{~g}$ about $9,000 \mathrm{ft}$ of runway will be required to stop from groundspeed of 100 knots. Such scenario may indeed occur on runways covered with thin ice and no use of thrust-reversers (Daidzic and Shrestha, 2008; Daidzic, 2009a, 2009c, 2011a, 2011b).

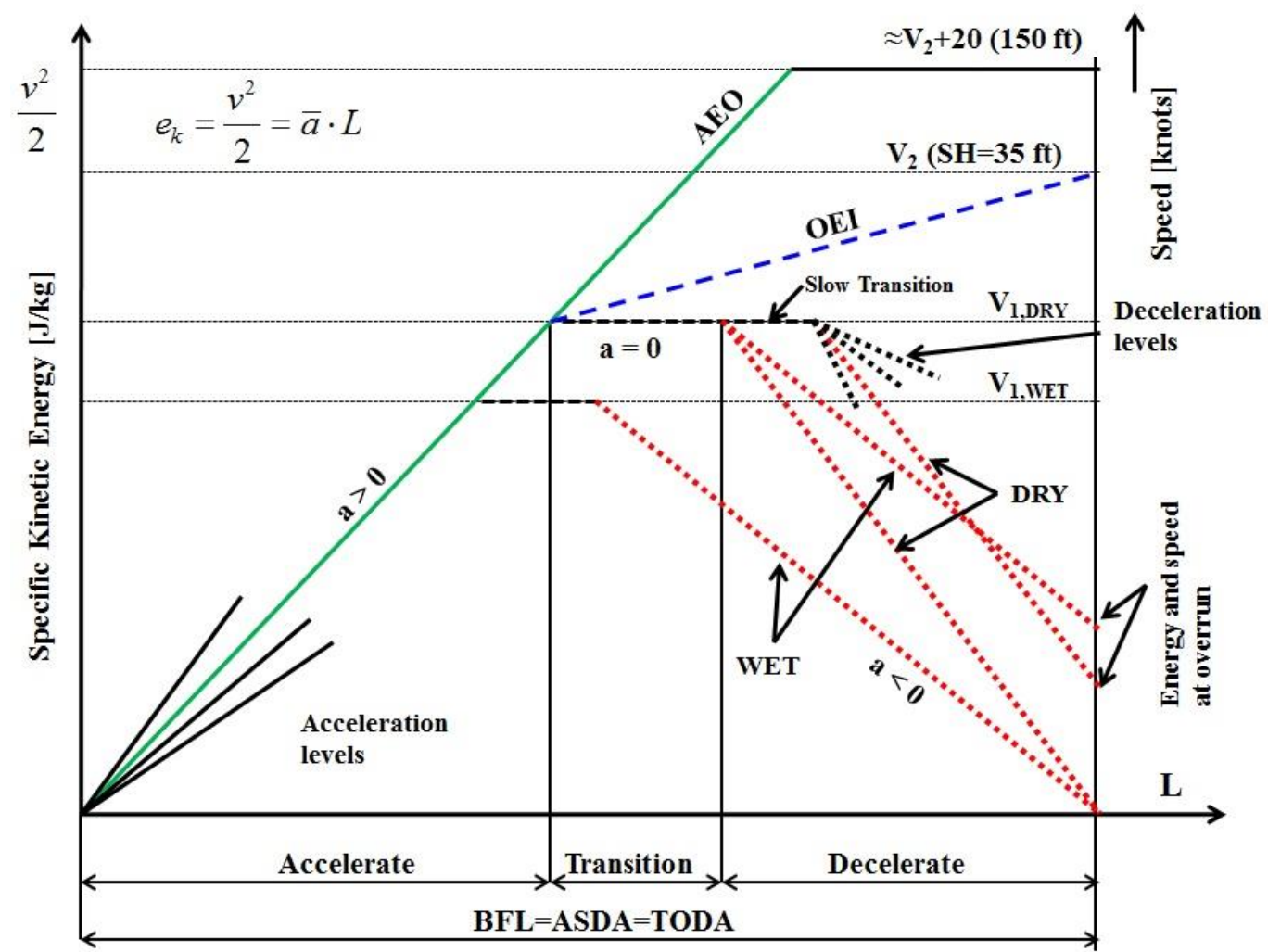

Figure 7. Average constant takeoff acceleration and deceleration levels. Accelerate-stop and accelerate-go BFL takeoff maneuver. Not so scale.

On the other hand, an airplane experiencing deceleration of $0.4 \mathrm{~g}\left(4 \mathrm{~m} / \mathrm{s}^{2}\right.$ or $12.8 \mathrm{ft} / \mathrm{s}^{2}$ ) such as during powerful braking on dry porous asphalt runway with the new tires it would only take 1,100 ft to stop from 100 knots. A takeoff utilizing maximum thrust AEO acceleration would closely resemble average 0.3g (9.66 $\mathrm{ft} / \mathrm{s}^{2}$ ) net acceleration requiring about 2,900 ft to accelerate to 140 knots from standstill.

\section{Results and Discussion}

The mathematical model developed earlier enabled us to compute various cases of runway go-around PNRs. That would include short and long runways, 
contaminated and dry runways, variable environmental conditions, variable landing touchdown speed (kinetic energy) and distance from the threshold, the effect of airplane weight, etc. To perform exhaustive parametric study of all different cases would require the article tenfold in size. Thus, we are only presenting more relevant results.

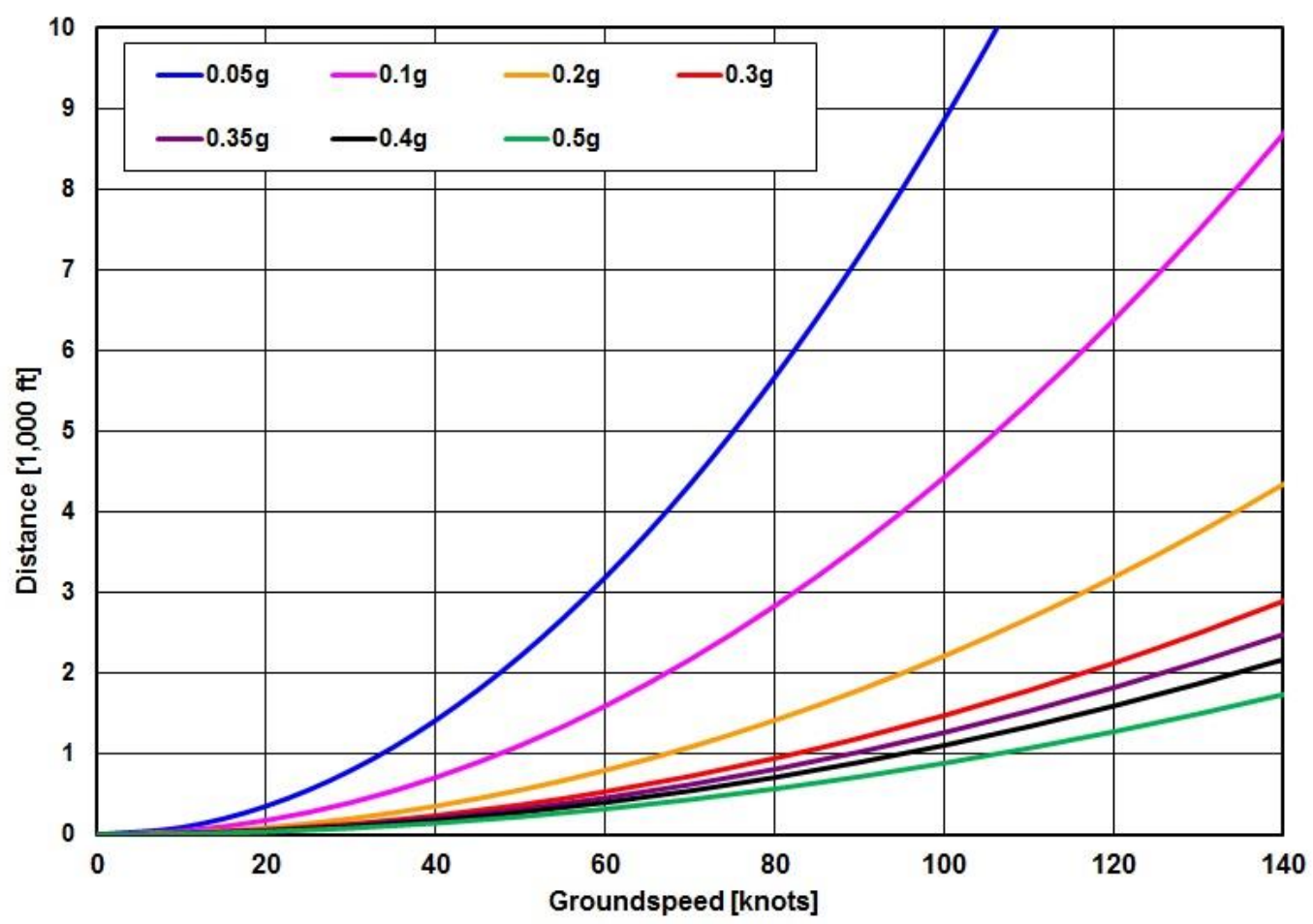

Figure 8. Acceleration/Deceleration levels and distances versus speed.

As discussed above, one of the main reasons rejected landing roll maneuver would be attempted, is to prevent overrun on slippery runways and/or after touching down fast and long. Computations of required landing distances on dry and wet runways at various touchdown points and speeds are shown in Figure 9. A time interval of three seconds was used for lowering of nose-gear without appreciable loss of speed. The attribute WET was actually used to designate combined contaminated runway providing deceleration of about $6.44 \mathrm{ft} / \mathrm{s}^{2}(0.2 \mathrm{~g})$.

An airplane landing on dry runway (Figure 9) at excessive touchdown speed of 160 knots and main-gear touchdown point at 3,500 ft would still be able to stop on a 8,000-ft runway utilizing combined $0.35 \mathrm{~g}$ deceleration ("good" braking). However, the same airplane landing on a slippery runway $(0.2 \mathrm{~g}$ 
combined deceleration - with or without thrust-reversers), and even touching down at proper distance of 1,500 ft, would just barely avoid overrun at touchdown speed of 160 knots if LDA is 8,000 ft. If the airplane's main gear touched down at $3,500 \mathrm{ft}$ runway distance, the overrun would occur even at touchdown speeds as low as 131 knot with 8,000 ft runway and about 146 knot with 9,000 ft LDA. Reference speed for a given airplane is 125 knots.

The main question arises: if the pilots realized that the landing roll deceleration is too weak and likely leading to overrun, could they still execute goaround and safely take off on remaining runway, while meeting all regulatory requirements? In order to answer this important question, results of simulation for decelerate-accelerate landing-takeoff maneuver are presented. The results presented in Figure 10, provide the relationship between $V_{T D}$ and $V_{\text {PNR }}$, as well as times from nose-gear down moment (NGTD) until reaching PNRs (dashed lines) at three different runaway touchdown locations.

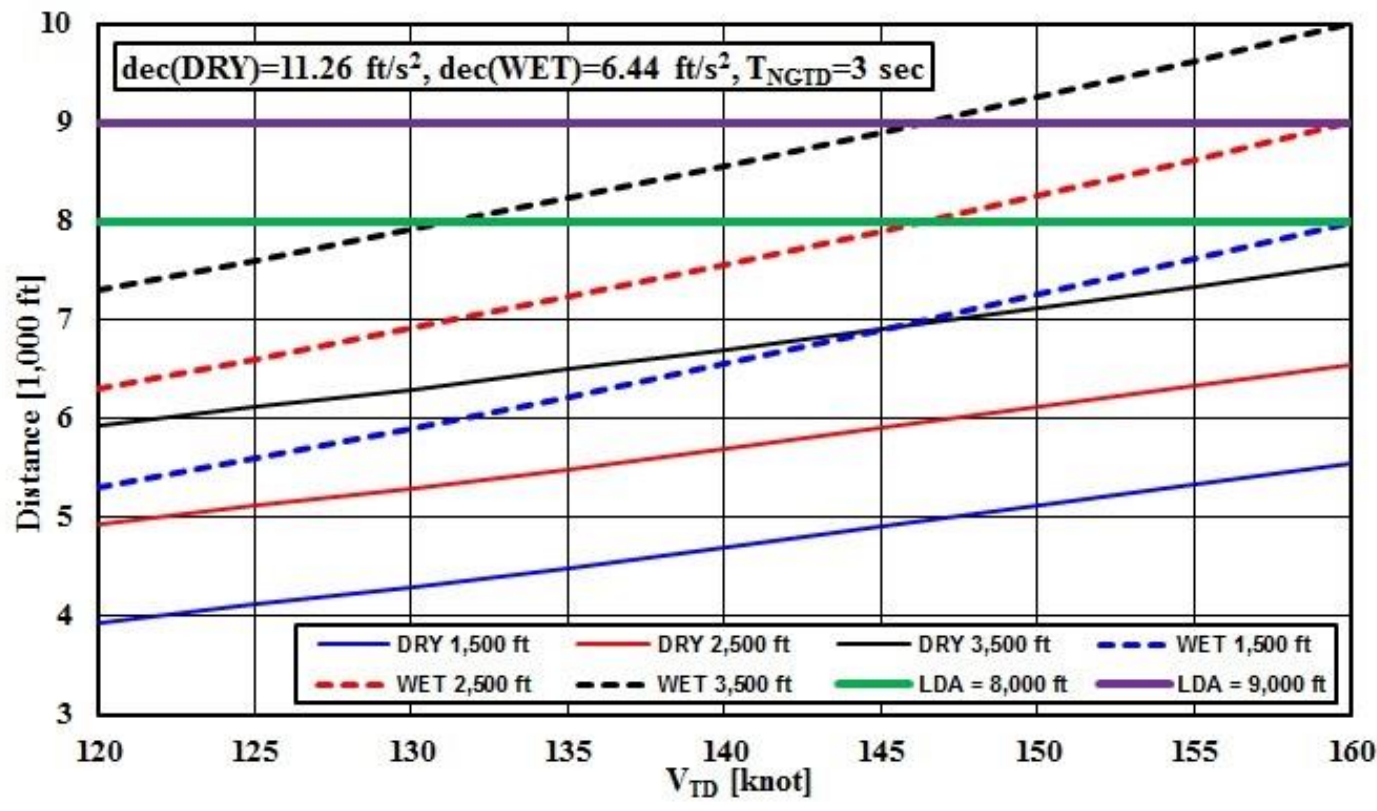

Figure 9. Stopping distance on 8,000 and 9,000 ft LDA runways at various touchdown distances and speeds for dry and slippery braking conditions.

In these results it is assumed that one-engine suddenly becomes inoperative at the moment of reaching PNR and TOGA applications. Thus all goaround accelerations are with OEI. The coasting dead-time (inertia) is taken as 2 seconds at PNR speed to be compatible with the FAR 25.109. For example, an 
airplane touching down on an 8,000-ft LDA runway at 2,500 ft and accounting for given rates of deceleration and OEI acceleration could theoretically slow down to 119 knots before initiation go-around. Pilots will have about 11 seconds from nose-gear touchdown to evaluate deceleration levels and make critical decision to abandon landing roll and go-around. From the deceleration rate it can be concluded that no thrust reversers are used and the runway is very slippery, so PNR go-around could be an option to avoid almost certain overrun.

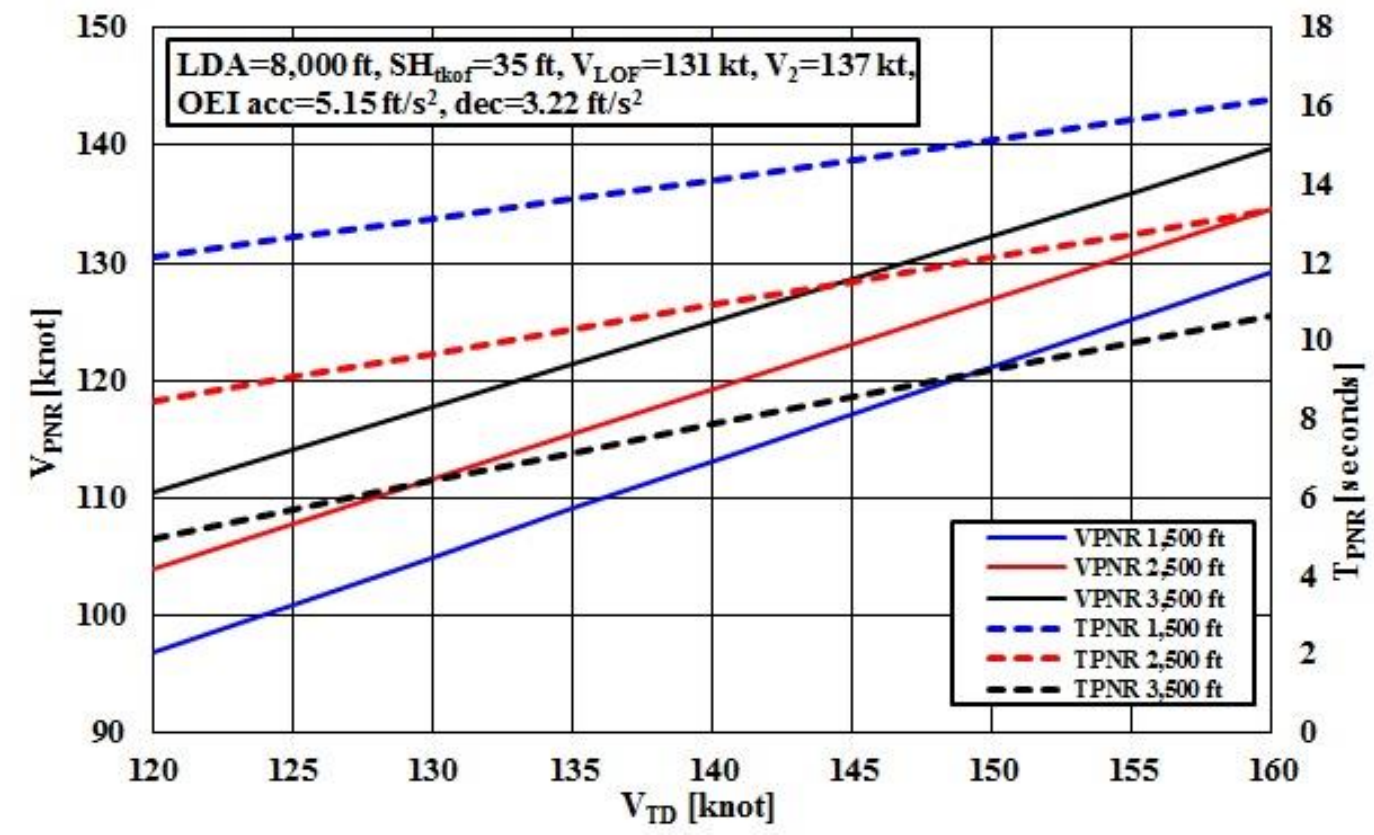

Figure 10. PNR speed (solid) and time (dashed) on a slippery 8,000 ft runway at various touchdown distances and speeds with go-around and given decelerations.

For the same runway, environmental, and airplane conditions as above, but having 9,000 ft LDA (Figure 11), the pilots could slow down to 113 knots (from 140 knots touchdown speed at 2,500 ft) and will have about 14 seconds to make decision to abort landing and execute OEI running takeoff and achieve $35 \mathrm{ft}$ and $V_{2}$ at DER SH. As expected longer runway will give pilots more time and the ability to slow down to lower speeds while making decisions to attempt to stop or accelerate and take off. Computational results for the case of 9,000 ft runway as shown graphically in Figure 11 are summarized numerically in Table 1. At longer touchdown points the pilots can only slow down to progressively faster speeds and have less time to make decisions to go-around. Longer runways normally offer pilots more time and alternatives, but what really counts is the runway remaining after touchdown and the available airplane's kinetic energy level. 


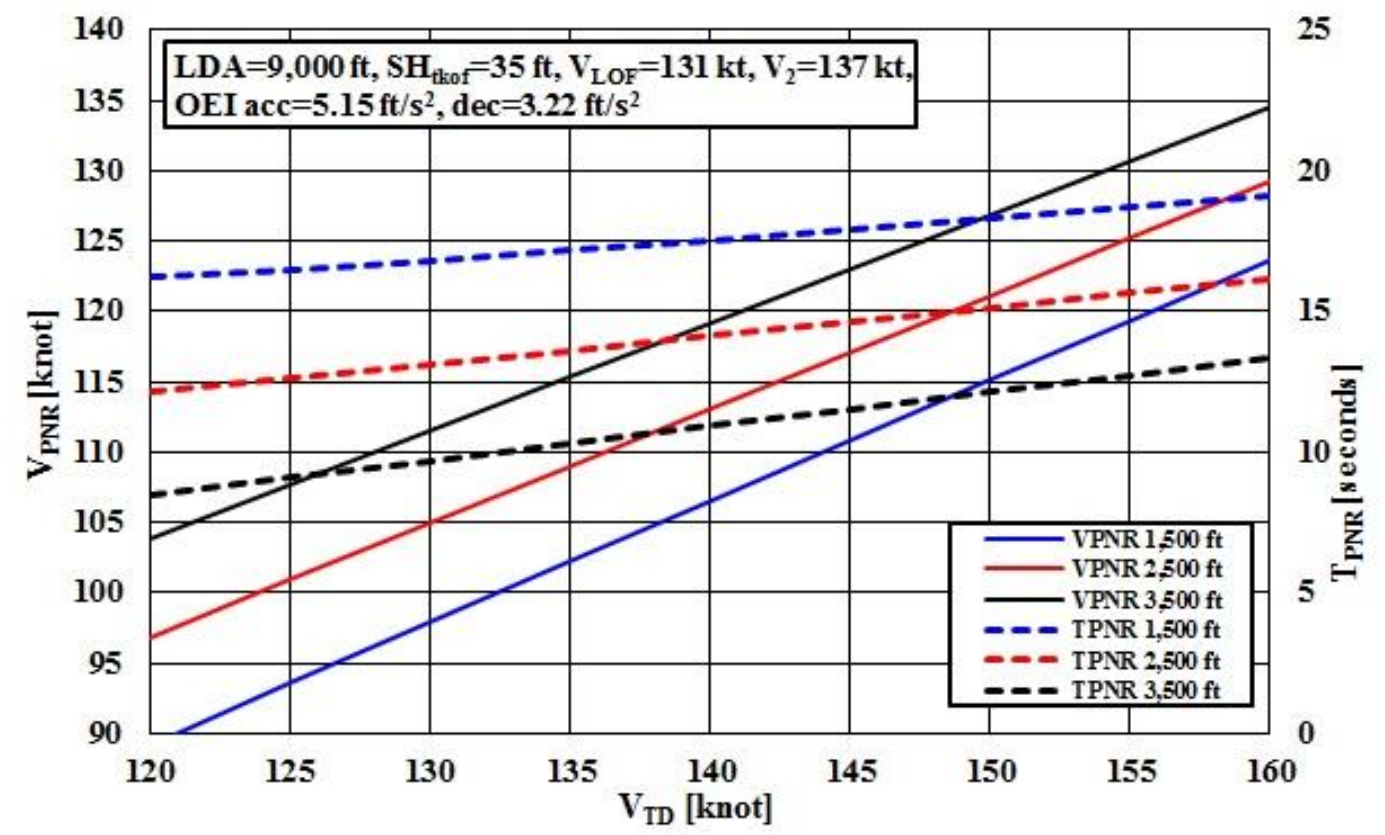

Figure 11. PNR speed and time on a slippery 9,000 ft runway at various touchdown distances and speeds for OEI go-around and given decelerations.

Table 1

PNR speeds (knots) and times (seconds) for $L D A=9,000 \mathrm{ft}$ and conditions given in Figure 11

\begin{tabular}{c|cccccc}
\hline \multirow{2}{*}{$\mathbf{V}_{\text {TD }}[\mathbf{k n o t}]$} & \multicolumn{6}{|c}{$\mathbf{L}_{\text {AIR }}[\mathbf{f t}]$} \\
\cline { 2 - 7 } & \multicolumn{2}{|c}{$\mathbf{1 , 5 0 0}$} & \multicolumn{2}{c}{$\mathbf{2 , 5 0 0}$} & \multicolumn{2}{c}{$\mathbf{3 , 5 0 0}$} \\
\cline { 2 - 7 } & $\mathbf{V}_{\text {PNR }}$ & TPNR & $\mathbf{V}_{\text {PNR }}$ & $\mathbf{T}_{\text {PNR }}$ & $\mathbf{V}_{\text {PNR }}$ & $\mathbf{T}_{\text {PNR }}$ \\
\hline 120 & 89.12 & 16.20 & 96.79 & 12.17 & 103.89 & 8.45 \\
125 & 93.56 & 16.49 & 100.88 & 12.65 & 107.70 & 9.07 \\
130 & 97.94 & 16.81 & 104.96 & 13.14 & 111.52 & 9.69 \\
135 & 102.29 & 17.16 & 109.02 & 13.63 & 115.35 & 10.31 \\
140 & 106.61 & 17.51 & 113.08 & 14.12 & 119.18 & 10.92 \\
145 & 110.90 & 17.89 & 117.12 & 14.62 & 123.03 & 11.53 \\
150 & 115.16 & 18.28 & 121.16 & 15.13 & 126.87 & 12.13 \\
155 & 119.39 & 18.68 & 125.19 & 15.64 & 130.72 & 12.74 \\
160 & 123.61 & 19.09 & 129.21 & 16.15 & 134.57 & 13.34 \\
\hline
\end{tabular}


The next two results presented will address the effect of acceleration and deceleration magnitudes. Again, 8,000 and 9,000 ft runways will be used with unchanged OEI acceleration starting at PNR/TOGA condition. However, this time deceleration will be on dry runways with good braking characteristics (combined $0.4 \mathrm{~g}$ ). Results for PNR calculations on a dry 8,000 ft runway for various touchdown points and speeds are graphically presented in Figure 12. It immediately becomes clear that airplanes can slow down to much lower speeds, but the time available between the nose-gear touchdown and PNR is halved compared to slow deceleration case (Figure 10). This may be very misleading as the pilots will actually have less time to make critical go-around decisions and may be deceived by the high deceleration magnitudes. This could be hazardous when landing long and/or fast on dry runway as was the case with the ill-fated B727 St. Thomas accident in 1976. Results for PNR calculations on a dry 9,000 ft runway for various touchdown points and speeds are graphically presented in Figure 13. Values of PNR speeds and times for an $\mathrm{LDA}=9,000 \mathrm{ft}$ dry runway conditions are presented in Table 2. For operational use, the speeds would be rounded to the nearest larger integer (e.g., 93.55 knots becomes 94 knots), while times could be rounded to nearest lower integer (e.g., 9.32 seconds would become 9 seconds) for additional safety margins.

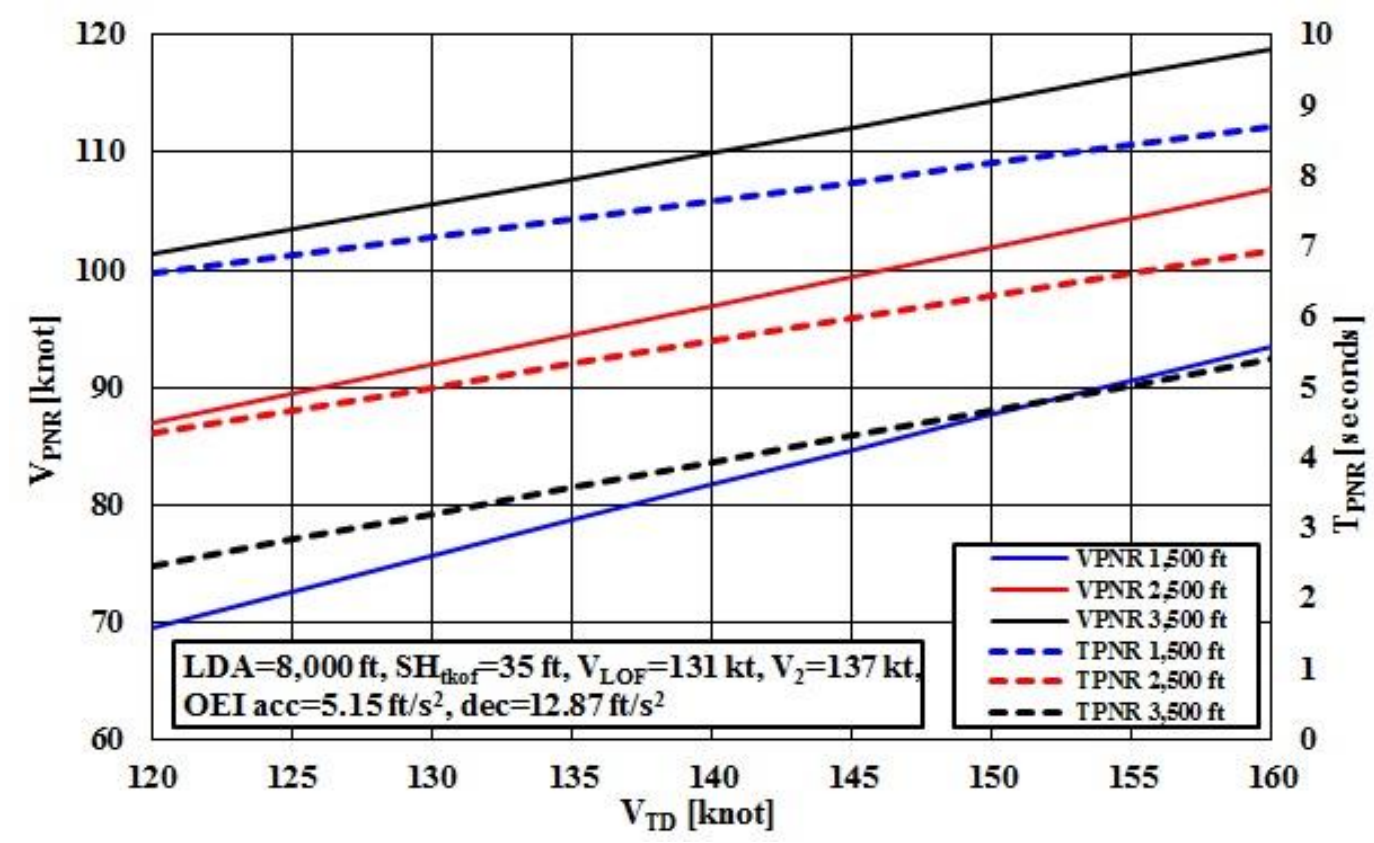

Figure 12. PNR speed (solid) and time (dashed) results on a dry LDA=8,000 ft runway at various touchdown distances and speeds for OEI go-around and given deceleration magnitude. 


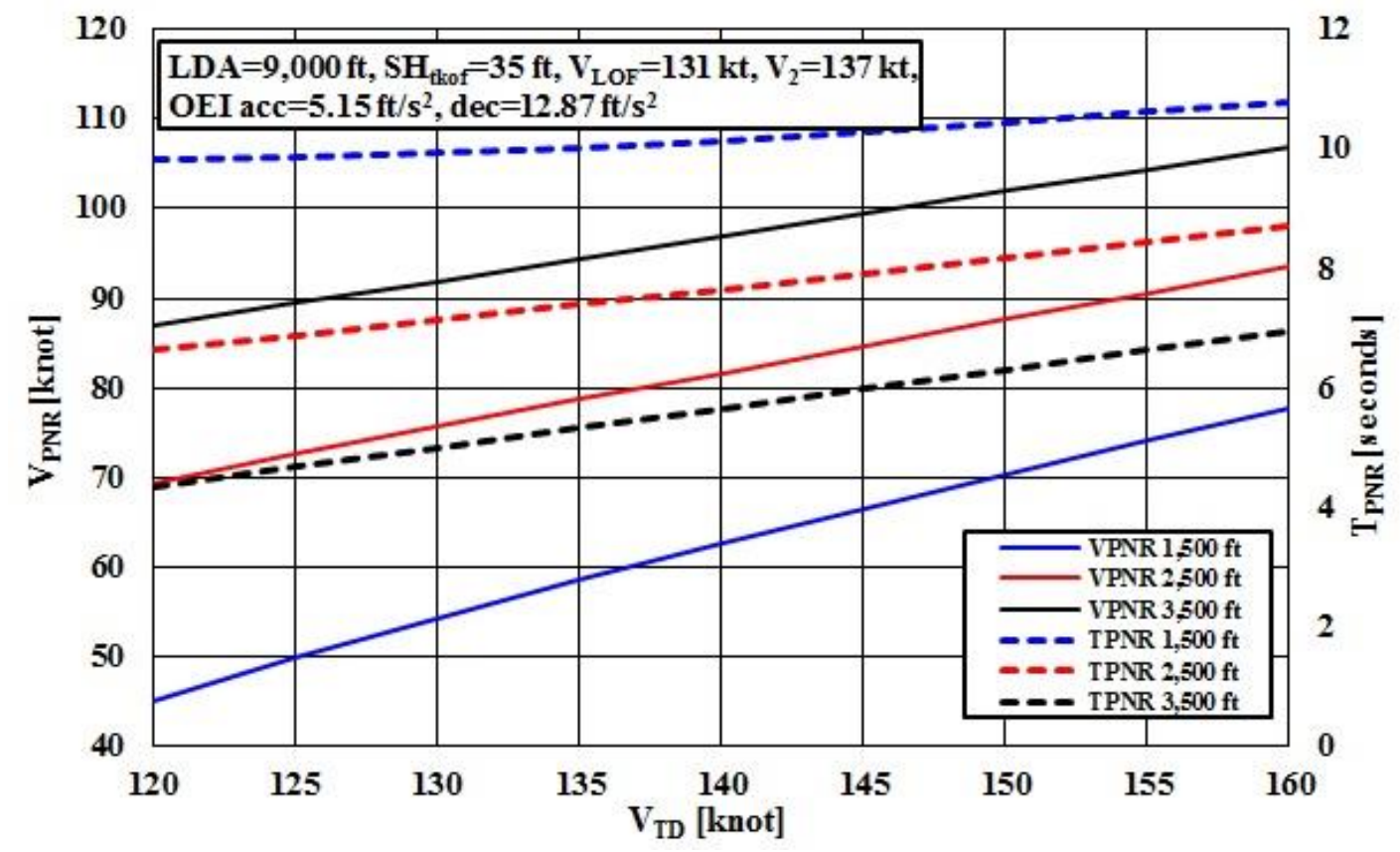

Figure 13. PNR speed (solid) and time (dashed) results on a dry LDA=9,000 ft runway at various touchdown distances and speeds and given deceleration.

Table 2

PNR speeds (knots) and times (seconds) for $L D A=9,000 \mathrm{ft}$ and conditions given in Figure 13

\begin{tabular}{c|cccccc}
\hline \multirow{2}{*}{$\mathbf{V}_{\text {TD }}[\mathbf{k n o t}]$} & \multicolumn{6}{|c}{$\mathbf{L}_{\text {AIR }}[\mathbf{f t}]$} \\
\cline { 2 - 7 } & \multicolumn{2}{|c}{$\mathbf{1 , 5 0 0}$} & \multicolumn{2}{c}{$\mathbf{2 , 5 0 0}$} & \multicolumn{2}{c}{$\mathbf{3 , 5 0 0}$} \\
\cline { 2 - 7 } & $\mathbf{V}_{\text {PNR }}$ & $\mathbf{T}_{\text {PNR }}$ & $\mathbf{V}_{\text {PNR }}$ & $\mathbf{T}_{\text {PNR }}$ & $\mathbf{V}_{\text {PNR }}$ & $\mathbf{T}_{\text {PNR }}$ \\
\hline 120 & 44.98 & 9.84 & 69.41 & 6.63 & 86.90 & 4.34 \\
125 & 49.81 & 9.86 & 72.53 & 6.88 & 89.38 & 4.67 \\
130 & 54.31 & 9.93 & 75.61 & 7.13 & 91.87 & 5.00 \\
135 & 58.57 & 10.02 & 78.66 & 7.39 & 94.37 & 5.33 \\
140 & 62.65 & 10.14 & 81.68 & 7.65 & 96.88 & 5.65 \\
145 & 66.57 & 10.29 & 84.68 & 7.91 & 99.40 & 5.98 \\
150 & 70.36 & 10.44 & 87.66 & 8.18 & 101.93 & 6.30 \\
155 & 74.06 & 10.61 & 90.61 & 8.44 & 104.46 & 6.63 \\
160 & 77.66 & 10.80 & 93.55 & 8.71 & 107.01 & 6.95 \\
\hline
\end{tabular}

An ill-fated Hawker 800A Owatonna crash in 2008 was most likely the result of too slow deceleration (NTSB) due to multiple known and some 
undetermined reasons making overrun almost certain. After not experiencing any appreciable deceleration while the runway end was approaching rapidly, pilots have apparently aborted the landing roll and attempted go-around too late and below the PNR speed (past landing PNR). This led to unsuccessful takeoff and stall in ground effect resulting in high-speed impact with the terrain just past the runway's departure end. Becoming safely airborne after slowing below runway PNR speed is not possible. On the other hand, the main cause for B727-95 accident was landing too long with essentially no option to stop or to abort landing roll and go-around. Unfortunately, such information was not available to B727 crew and critical decisions were basically left to captain's feel. Both of these unfortunate fatal accidents are well described by the theoretical considerations presented here.

Some operators use simple guideline, which is to commit to landing roll deceleration under all circumstances once the thrust reversers are deployed. This is certainly common-sense and simple enough rule to follow, but not necessarily optimal or best in all situations. One has to consider that jet engine may take up to 8 seconds to spool up to TOGA thrust from idle. On the other hand, engines in reverse thrust will spool up quicker when reversers are re-stowed. One would really need to study the operation and dynamics of each particular jet engine to establish best practices in both cases - with and without thrust reversers. In any case, aborted landing roll and go-around may be an option that could prevent some overruns. However, such option only safely exists if initiated before the PNR point.

However, the real complication is that landings present very dynamic scenarios with many uncertainties as to the exact touchdown speeds and runway touchdown points, which cannot be controlled nearly as good as during normal takeoffs. Thus it is almost impossible for operators to schedule PNR go-around conditions. This is something that must be done in real time and during the actual operation in existing conditions. While a go-around after touchdown may be very rare in actual line operations, nevertheless it may easily result in fatal accidents if performed improperly. On the other hand, overrunning landing runways at highspeed is also not an option and could be avoided if proper go-around is initiated in flight or after touchdown. The problem is that pilots may not know beforehand what exactly to expect in terms of decelerations while on approach and can start sensing the actual conditions only after the landing roll deceleration started. Without the availability of the accurate and efficient airplane-runway energy detection, monitoring, management, and information system the point-of-noreturn runway location and speed becomes impossible to compute and depend on. 
The aviation industry has recognized the need for TOPM long time ago. But takeoff performance monitors alone are not sufficient to resolve landing PNR and go-around problems. Equally so, and perhaps even more important, are landing performance monitors, but such do not currently exist other than in rudimentary forms utilizing simple functions with the automatic brake systems.

For that purpose an airplane and runway energy measurement, monitoring, management and protection system which monitors, informs, and protects all runway operations was developed by AAR Aerospace Consulting, LLC and is called TRSS ${ }^{\mathrm{TM}}$. The total energy levels are monitored during takeoffs and landings in addition to following the longitudinal and lateral runway tracks and predicting motion along the runway based on measured accelerations, energy state, known environmental conditions, remaining runway, surface and tire condition, etc. It is hoped that such systems will significantly reduce runway landing and takeoff overruns, veer-offs, unsuccessful aborted landings, and other critical runway operations.

\section{Conclusions}

The decelerate-accelerate-takeoff maneuver in transport category airplanes has been discussed. Mathematical model based on conservation of total energy has been used to calculate the point-of-no-return on a runway which will still enable the airplane to safely execute go-around and achieve regulatory screen heights and takeoff safety speeds. After this point has been exceeded or below the point-of-no-return speed no go-around should ever be considered. It is better to accept overrun which may or may not result in severe crash. Landing long and fast and/or decelerating on slippery runways may very well result in an overrun which could be prevented if the go-around is attempted before reaching this critical runway condition. The point-of-no-return on the runway will depend on many factors with most important ones being the levels of deceleration and acceleration, remaining runway left after touchdown and touchdown speed, airplane configuration change and engine acceleration characteristics, AEO or OEI takeoff, use of thrust reversers, and many other more or less important factors. It is important that operators develop standard operating procedures and train pilots on how to execute such go-around maneuver. The main problem with landing go-arounds is that landing cannot be well defined in terms of remaining energy and touchdown points. Dynamic conditions exist which without the availability of the proper airplane and runway energy measurement, monitoring, management, and information system makes the point-of-no-return runway location and speed impossible to predict accurately. 


\section{Author Bio}

Dr. Nihad E. Daidzic is president of AAR Aerospace Consulting, L.L.C. He is also a full professor of Aviation, adjunct professor of Mechanical Engineering, and research graduate faculty at Minnesota State University, Mankato. His Ph.D. is in fluid mechanics and Sc.D. in mechanical engineering. He was formerly a research associate in applied physics at the Center for Microgravity Research and Applications at Vanderbilt University and a staff scientist at the National Center for Microgravity Research and the National Center for Space Exploration and Research at NASA Glenn Research Center in Cleveland, OH. He has also held various faculty appointments at Vanderbilt University, University of Kansas, and Kent State University. His current research interest is in theoretical, experimental, and computational fluid dynamics, micro- and nano-fluidics, aircraft stability, control, and performance, mechanics of flight, piloting techniques, and aerospace propulsion. Dr. Daidzic has authored more than 130 peer-reviewed journal, international conference, and professional industry magazines articles and has authored over 60 proprietary technical reports for NASA, DOE, ESA, etc. Dr. Daidzic is ATP and "Gold Seal" CFII/MEI/CFIG with flight experience in airplanes, helicopters, and gliders. 


\section{References}

Anderson, J. D. Jr. (1999). Aircraft performance and design. New York, NY: McGraw-Hill.

Asselin, M. (1997). An Introduction to Aircraft Performance. Reston, VA: American Institute for Aeronautics and Astronautics (AIAA).

Blake, W., \& Elliott, R. L. (1991, March). The last two minutes, Boeing Airliner, Jan.-March 1991, 1-9.

Daidzic, N. E., \& Shrestha, J. (2008). Airplane Landing Performance on Contaminated Runways in Adverse Conditions, Journal of Aircraft, 45(6), 2131-2144. DOI: $10.2514 / 1.38056$

Daidzic, N. E. (2008, December). When go-around is impossible - defining the point of no return. Professional Pilot, 42(12), 110-113.

Daidzic, N.E. (2009a) Aircraft Landing Operations on Contaminated Runways and Adverse Conditions, WATS 2009, World Aviation Training Conference, Rosen Shingle Creek Resort, Paper WATS 5.2, 28-30 April 2009, Orlando, FL.

Daidzic, N. E. (2009b, September). Avoiding veer-off accidents on contaminated runways, Professional Pilot, 43(9), 54-58.

Daidzic, N. E. (2009c, December). Avoiding overrun accidents on contaminated runways, Professional Pilot, 43(12), 104-107.

Daidzic, N. E. (2011a, March). Dealing with Contaminated Runways. The Journal for Civil Aviation Training (CAT), 2/2011, 29-32.

Daidzic, N.E. (2011b) Some Considerations for Regional Airline Operations on Contaminated Runways, WATS 2011, World Aviation Training Conference, Rosen Shingle Creek Resort, Paper RATS 6.3, April 19-21, 2011, Orlando, FL.

Daidzic, N.E. (2012a, March) FADEC advances allow better Engine Performance, Professional Pilot, 46(3), 78-82. 
Daidzic, N.E. (2012b, September) Jet Engine Thrust Ratings, Professional Pilot, 46(9), 92-96.

Daidzic, N. E. (2013a, August). T/O overruns and veer-offs on slippery runways with crosswinds, Professional Pilot, 47(8), 54-58.

Daidzic, N. E. (2013b, November). Aircraft tests arrive at numbers pilots need for safe operations, Professional Pilot, 47(11), 100-104.

Daidzic, N.E. (2014). A total-energy based model of airplane overspeed takeoffs. International Journal of Aviation Aeronautics Aerospace (IJAAA), 1(3), 125.

Daidzic, N.E. (2016). Determining the runway point-of-no-return for landing roll go-around in transport category airplanes, $\mathrm{A}^{3} \mathrm{IR}$ Aviation Research Conference 2016, Paper \#1210, January 14-17, 2016, Chandler AZ.

Davies, M. (Ed.) (2003). The standard handbook for aeronautical and astronomical Engineers. New York, NY: McGraw-Hill.

DeLoach, R., Marlowe, R. J., \& Yager T. (2009). Uncertainty analysis for the evaluation of a passive runway arresting system, 47th AIAA Aerospace Sciences Meeting including The New Horizons Forum and Aerospace Exposition Conference, Paper AIAA 2009-1156, January 5-8 2009, Orlando, FL. DOI: 10.2514/6.2009-1156

van Es, G. W. H., Roelen A. L. C., Kruijsen E. A. C, \& Giesberts, M. K. H. (2001). Safety aspects of aircraft performance on wet and contaminated runways (Report NLR-TP-2001-216), Amsterdam, The Netherlands: NLR Air Transport Safety Institute.

van Es, G. W. H. (2005). Running out of runway: Analysis of 35 years of landing overrun accidents (Report NLR-TP-2005-498), Amsterdam, The Netherlands: NLR Air Transport Safety Institute.

van Es, G. W. H. (2010). A study of runway excursion from a European perspective (Report NLR-CR-2010-259), Amsterdam, The Netherlands: NLR Air Transport Safety Institute.

Eshelby, M. E. (2000). Aircraft performance: Theory and practice. Boston, MA: Elsevier. 
Filippone, A. (2006). Flight performance of fixed and rotary wing aircraft. Reston, VA: American Institute for Aeronautics and Astronautics (AIAA).

Hale, F. J. (1984). Introduction to aircraft performance, selection, and design. New York, NY: John Wiley \& Sons.

Jeppesen. (2007). Performance. (JAA ATPL Training, Edition 2, JA 310109-002, Book 9, JAR Ref. 032, ISBN 0-88487-496-6). Neu-Isenburg, Germany: Atlantic Flight Training, Ltd., Sanderson Training products, Jeppesen $\mathrm{GmbH}$.

Job. M. (1994). Air disaster - Volume 1. Weston Creek, Australia: Aerospace Publications Pty Ltd.

Mair, W. A., \& Birdsall, D. L. (1992). Aircraft performance. Cambridge, UK: Cambridge University Press.

McCormick, B. W. (1995). Aerodynamics, aeronautics and flight mechanics (2nd ed.). New York, NY: John Wiley \& Sons.

McKinney, D. (1999). Flight Safety Foundation approach-and-landing accident reduction task force operations and training working group final report (SAE Paper 1999-01-5585). Warrendale, PA: Society of Automotive Engineers (SAE).

Padilla, C. E. (1996). Optimizing jet transport efficiency: Performance, operations, and economics. New York, NY: McGraw-Hill.

Roskam, J., \& Lan, C. T. (1997). Airplane aerodynamics and performance, Lawrence, KS: DAR Corporation.

Saarlas, M. (2007). Aircraft performance. Hoboken, NJ: John Wiley \& Sons.

Shevell, R. S. (1989). Fundamentals of flight. Englewood Cliffs, NJ: Prentice Hall.

Spiegel, M. R., \& Liu, J. (1999). Mathematical handbook of formulas and tables (2nd ed.). New York, NY: McGraw-Hill.

Swatton, P. J. (2008). Aircraft performance: Theory and practice for pilots (2nd ed.). Chichester, UK: John Wiley \& Sons. 
Torenbeek, E., \& Wittenberg, H. (2009). Flight physics, Amsterdam, The Netherlands: Springer.

US Department of Transportation, Federal Aviation Administration. (1994). Takeoff safety training aid (AC 120-62). Washington, DC: Author.

US Department of Transportation, Federal Aviation Administration. (2007). A study of normal operational landing performance on subsonic, civil, narrow-body jet aircraft during instrument landing system approaches (Final Report DOT/FAA/AR-07/7), Washington, DC: Author.

US Department of Transportation, Federal Aviation Administration. (2012). Engineered Materials Arresting Systems (EMAS) for Aircraft Overruns (Advisory Circular AC 150/5220-22B). Washington, DC: Author.

US Department of Transportation, Federal Aviation Administration. (2013). Part 25, Airworthiness Standards: Transport Category Airplanes. Washington, DC: Author.

US Department of Transportation, Federal Aviation Administration. (2014a). Airport design (Advisory Circular AC 150/5300-13A). Washington, DC: Author.

US Department of Transportation, Federal Aviation Administration. (2014b). Part 121, Operating Requirements: Domestic, Flag, and Supplemental Operations. Washington, DC: Author.

Vinh, N. X. (1993). Flight mechanics of high-performance aircraft. Cambridge, UK: Cambridge University Press.

Wagenmakers, J. (1991). Aircraft performance engineering. New York, NY: Prentice Hall.

Zammit-Mangion, D., \& Eshelby, M. (2005). Design and integration of a take-off monitor display, AIAA Atmospheric Flight Mechanics Conference and Exhibit, August 15-18 2005, San Francisco, CA. DOI: 10.2514/6.20056218

Zammit-Mangion, D., \& Eshelby, M. (2006). Evaluation of takeoff performance monitoring algorithm in large transport operations, Journal of Aircraft, 43(1), 201-206. DOI: 10.2514/1.2974 